\title{
PROSPECTIVE STUDY OF TREATMENT OF NON-UNION OF TIBIA USING LIMB RECONSTRUCTION SYSTEM WITH INTRAMEDULLARY NAILING
}

\author{
Sharat Balemane ${ }^{1}$, Mohamed Adham² \\ ${ }^{1}$ Assistant Professor, Department of Orthopaedics, Yenepoya Medical College. \\ ${ }^{2}$ Postgraduate, Department of Orthopaedics, Yenepoya Medical College.
}

\section{ABSTRACT}

\section{BACKGROUND}

To assess combination of an intramedullary interlocking nail with LRS in cases of infected non-union tibia and to show influence of nail in predicting good outcome.

\section{METHODS}

From 2014 to 2016, records of 20 patients (17 men and 3 women) aged 18 to 65 years (Mean, 38.4 years) with infected nonunion of the tibia treated with the Limb Reconstruction System over intramedullary interlocking nail technique were prospectively reviewed. According to Jain et al patients were classified into 5 cases of type A1, 5 cases of type A2, 7 cases of type B1 and 3 cases of type B2. All cases underwent LRS and IMIL. Mean amount of target lengthening was $54.65 \mathrm{~mm}$. The mean follow-up was 14 months.

\section{RESULTS}

Mean amount of tibia lengthening was $51.70 \mathrm{~mm}$. Leg length equalisation was achieved in 19 cases (+/-5). According to modified scoring by Paley et al, 12 patients had excellent results, 3 patients had good, 4 patients had fair outcome and 1 patient had poor outcome. Mean distraction index was 0.97. Mean maturation index was 2.43. Mean consolidation index was 3.47. Mean healing index was 1.40. One case had proximal locking screw failure. One case developed pre-mature consolidation as distraction was started at delayed period due to non-compliance. Two cases developed decreased dorsiflexion of ankle. Two cases required flap surgeries for cover of bone. One case had pin breakage, which had to be exchanged. One case developed re-infection.

\section{CONCLUSION}

The advantages of this technique include complete eradication of infective foci, reduced risk of deformity during lengthening, decreased risk of fractures post external fixator removal and reduction of time required for external fixator use, thus decreasing healing index : number of days of external fixation required per centimetre of lengthening.

\section{KEYWORDS}

Infected Non-Union Tibia, Limb Reconstruction System, Intramedullary Interlocking Nail.

HOW TO CITE THIS ARTICLE: Balemane S, Adham M. Prospective study of treatment of non-union of tibia using limb reconstruction system with intramedullary nailing. J. Evolution Med. Dent. Sci. 2016;5(70):5091-5095, DOI: $10.14260 /$ jemds/2016/1156

\section{INTRODUCTION}

Goals of treatment in infected non-union tibia are to obtain solid bony union, eradication of infection with maximum functional use of extremity. Different modalities of management like extensive debridement and local soft tissue flaps using antibiotic beads, cancellous bone grafts, allografts and vascular fibular grafts have been in use for decades.

Essence is to obtain infection free environment and plan to proceed for stabilisation and stimulation of healing patterns. These procedures are usually staged requiring one or more procedures and thus prolonging recovery period. They have variable rate of success and are unable to usually accomplish length and stability.

On the other hand, Ilizarov and Limb Reconstruction System ${ }^{1}$ have been found to show encouraging results as they offer one stage procedure with eradication of infection,

Financial or Other, Competing Interest: None.

Submission 01-07-2016, Peer Review 30-07-2016,

Acceptance 05-08-2016, Published 01-09-2016.

Corresponding Author:

Dr. Mohamed Adham,

\#104 A Block, Gardyenia Hostel,

Yenepoya Medical College,

Derlakatte, Mangalore-575018.

E-mail: drmdadham99@gmail.com

DOI: $10.14260 /$ jemds/2016/1156 correction of length and deformity. A significant modification of these methods is combining an intramedullary interlocking nail with Limb Reconstruction System. The advantage of using this method is reduced risk of deformity during lengthening, decreased rate of fractures and deformity, post external fixator removal and reduction of time required for external fixator use.

Aim of the study is to show the eradication of infection and influence of intramedullary interlocking nail in reducing time needed for external fixator removal, reducing the deformities and impact on healing index: number of days of external fixation required per centimetre of lengthening.

\section{METHODS}

\section{Study Group}

Lengthening over intramedullary interlocking nail from 2014 to 2016, records of 20 patients (17 men and 3 women) aged 18 to 65 years (Mean, 34.5 years) with infected non-union of the tibia treated with the Limb Reconstruction System over intramedullary interlocking nail technique were followed up. All cases were monitored for one and a half years; 16 cases occurred after open fractures, one had infection post fasciotomy which was done due to impending compartment syndrome, and 3 cases had infection following plate osteosynthesis. 16 Fractures occurred as a result of road traffic 
accident and four had fall.13 Open fracture cases had type II wound and 3 had type III wounds according to Gustillo Anderson classification (Table 1). All open fractures except four were initially treated with debridement and external fixator. While one was treated with IMIL nail after thorough debridement. The mean follow-up was 14 months (12-17 months).

\begin{tabular}{|c|c|c|c|c|c|}
\hline $\begin{array}{c}\text { Mechanism } \\
\text { of Injury }\end{array}$ & $\begin{array}{c}\text { Number } \\
\text { of Cases }\end{array}$ & \multicolumn{2}{|c|}{$\begin{array}{c}\text { Aetiology } \\
\text { Road Traffic } \\
\text { Fall From } \\
\text { Accident Height }\end{array}$} & $\begin{array}{c}\text { Extra -Medullary } \\
\text { Osteotomy } \\
\text { Metaphyseal } \\
\text { Diaphyseal }\end{array}$ \\
\hline $\begin{array}{c}\text { Open } \\
\text { Fractures }\end{array}$ & 16 & $\begin{array}{c}\text { Gustillo Anderson } \\
\text { Type II-13 } \\
\text { Type III-3 }\end{array}$ & 14 & 2 & 12 \\
\hline $\begin{array}{c}\text { Post } \\
\text { Fasciotomy }\end{array}$ & 1 & 3 & 1 & 2 & 3 \\
\hline $\begin{array}{c}\text { Infectious } \\
\text { Osteosynthesis }\end{array}$ & \multicolumn{2}{|c|}{ Table 1 } & 1 & 3 \\
\hline \multicolumn{2}{|c|}{} \\
\hline
\end{tabular}

\section{Criteria for Evaluation}

We modified scoring system of Paley et $\mathrm{al}^{2}$ (Table 2) for outcome of tibia lengthening procedure on basis of clinical and radiological criteria. The scores were rated as excellent, good, fair or poor and were calculated on the basis of number of points that were assessed for five parameters: range of motion of ankle, amount of lengthening, gait, pain and ability to perform daily activities/work. The range of motion of the ankle was determined on the basis of the amount of equinus deformity and the amount of dorsi flexion at the end of treatment or before treatment. Lengthening was assessed by
Orthofix LRS was used in all cases combined with $8 / 9 \mathrm{~mm}$ IMIL nails. Location of non-union was proximal diaphyseal in 9 cases and distal diaphyseal in 11 cases. Non-unions were classified according to Jain et al into 5 cases of A1, 5 cases of type A2, 7 cases of type B1 and 3 cases of type B2.

\begin{tabular}{|c|c|c|c|c|c|c|c|c|}
\hline & \begin{tabular}{|c|} 
Excellent \\
$(25$ Points $)+$
\end{tabular} & $\begin{array}{c}\text { Good } \\
(20 \text { Points })+ \\
\end{array}$ & $\begin{array}{c}\text { Fair } \\
(10 \text { Points })+\end{array}$ & $\begin{array}{c}\text { Poor } \\
\text { (0 Point)+ }\end{array}$ & $\begin{array}{l}\text { Excellent } \\
\text { (0 Points)- }\end{array}$ & $\begin{array}{c}\text { Good } \\
\text { (10 Points)- } \\
\end{array}$ & $\begin{array}{c}\text { Fair } \\
(20 \text { Points })-\end{array}$ & $\begin{array}{c}\text { Poor } \\
(25 \text { Points })- \\
\end{array}$ \\
\hline $\begin{array}{l}\text { Range of Motion } \\
\text { of Ankle }\end{array}$ & $\begin{array}{c}\text { Full Dorsi } \\
\text { Flexion }\end{array}$ & $\begin{array}{l}\text { Dorsi Flexion } \\
\text { upto Neutral }\end{array}$ & $\begin{array}{c}\text { Less than } \\
\text { Neutral }\end{array}$ & $\begin{array}{c}\text { Fixed Equinus } \\
\text { Deformity }\end{array}$ & & & & \\
\hline $\begin{array}{c}\text { Amount of } \\
\text { Lengthening }\end{array}$ & $\begin{array}{l}\text { Within } 0.5 \\
\mathrm{~cm} \text { of goal }\end{array}$ & $\begin{array}{c}\text { Within } \\
1 \mathrm{~cm}\end{array}$ & $\begin{array}{l}\text { Within } \\
2 \mathrm{~cm}\end{array}$ & $>2 \mathrm{~cm}$ & & & & \\
\hline Gait & 0 & 1 & 1 & 2 & & & & \\
\hline Pain & & & & & 0 & 1 & 2 & 3 \\
\hline Daily Activities & & & & & 0 & 1 & 1 & 2 \\
\hline \multicolumn{9}{|c|}{ Table 2} \\
\hline
\end{tabular}

- $\quad$ Excellent $>95$ points, good $75-94$, fair $40-74$, poor $<40$ points.

- Gait: 0-no limp, 1=slight limp, 2=moderate limp.

- Pain: $0=$ no pain, $1=$ slight pain, $2=$ moderate pain, $3=$ severe pain.

- Activity: $0=$ full time work, $1=$ reduced activity, $2=$ no activity.

- $\quad+=$ add the points.

- $\quad$-=subtract the points.

Operative time, estimated blood loss and cost of treatment were also recorded. Radiographs were made monthly throughout the consolidation phase. The maturation phase began at the end of distraction (the limb-lengthening phase) and ended when the bone in the distraction gap had healed sufficiently (when three of four cortices were seen to be intact on antero-posterior and lateral radiographs, the radiographic consolidation end point]). With use of the Ilizarov fixator, lengthening occurs along the mechanical axis of the tibia, whereas lengthening over an intramedullary nail occurs along the anatomical axis. comparing the actual amount of lengthening with the initial goal. Gait was evaluated according to the degree of limp (Subjectively assessed on clinical examination) preoperatively compared with postoperatively. The amount of pain was assessed subjectively by the patient before and after treatment, as was the ability to perform activities of daily living and to work. Through the addition and subtraction of point values, the patient received a score that was excellent (95 to 100 points), good (75 to 94 points), fair (40 to 74 points) or poor (less than 40 points).
Distraction index, maturation index and consolidation index were calculated according to Chart 1.3

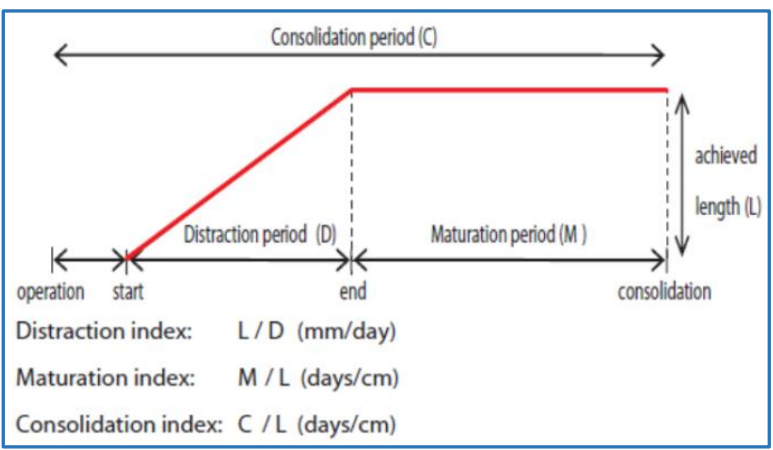

\section{Chart 1}

\section{Surgical Technique}

The most important principle of technique was to avoid contact between the IM nail and Shanz pins. ${ }^{2}$ The image intensifier was used in the operating room to obtain careful antero-posterior, lateral and oblique views. One problem which was encountered in the population was smaller tibial dimension including narrower tibial medullary canals, which 
frequently required the use of an $8 \mathrm{~mm}$ diameter intramedullary interlocking nail.

\section{Step 1: Debridement and Osteotomy of Infected Site}

Patients were operated under spinal anaesthesia. Preoperatively, methylene blue was injected into sinuses for complete excision of the sinus tracts. Existing implants were removed, thorough debridement of infected tissue was done and the bone was resected transversely proximal and distal to non-union site to remove all circumferential defects till punctate bleeding was noticed. The medullary canal was opened on both sides. Punctate cortical bleeding (Paprika sign) was used to determine the completeness of bone debridement.

\section{Step 2: Intramedullary Nail Insertion}

Tibial nail was inserted through a transpatellar incision. Tibia was reamed $1 \mathrm{~mm}$ over the planned tibial nail diameter, intramedullary nail was inserted, proximal end of the nail was locked using two medial-to-lateral locking screws.

\section{Step 3: Tibial Corticotomy}

This metadiaphyseal junction offers superior regenerate for bone formation. Diaphyseal osteotomy was avoided as much as possible. Corticotomy was performed using a $1 / 2 \mathrm{~cm}$ corticotome (Fig. 2).

Step 4: Application of the Limb Reconstruction System

A $6 \mathrm{~mm}$ Shanz pins were inserted into the tibia with 2 pins above corticotomy site, 2 pins in the middle segment and 2 pins distal to non-union site and pins were connected using LRS, rails attached with 2 end clamps and 1 central clamp connected with compression and distraction device (Fig. 2).

\section{Step 5: Postoperative Care}

Rest and elevation of the leg was given for 1 to 3 days.

Quadriceps straight-leg raise exercises and knee range of motion was started immediate post-operatively.

Ambulation was started with the patient's partial weightbearing (50\%) with crutches or a walker after 3 days.

Distraction was started on the $8^{\text {th }}$ day. The distraction rate was $1 \mathrm{~mm}$ per day in two phases (Fig. 3).

Patients were discharged from hospital on the $14^{\text {th }}$ postoperative day.

Distraction was stopped when the desired tibial length was achieved (Fig. 4).

\section{Step 6: Frame Removal}

The desired tibial length was usually reached after 1 to 3 months. LRS was removed during maturation period once maturation period was equal to distraction period (Fig. 5).

\section{Step 7: Follow-Up}

Regular follow-up X-rays were obtained every month until the distracted callus had fully matured (Fig. 6). Full weightbearing without walking aids, running and jumping was permitted when complete consolidation at the distraction site was seen.

\section{RESULTS}

\begin{tabular}{|c|c|c|c|c|c|c|c|c|c|c|}
\hline Patient & $\mathbf{1}$ & $\mathbf{2}$ & $\mathbf{3}$ & $\mathbf{4}$ & $\mathbf{5}$ & $\mathbf{6}$ & $\mathbf{7}$ & $\mathbf{8}$ & $\mathbf{9}$ & $\mathbf{1 0}$ \\
\hline Age & 26 & 34 & 38 & 65 & 18 & 36 & 28 & 45 & 35 & 29 \\
\hline Target Length & 45 & 54 & 56 & 46 & 64 & 58 & 66 & 48 & 58 & 62 \\
\hline Length Achieved & 44 & 54 & 56 & 41 & 63 & 52 & 65 & 48 & 55 & 61 \\
\hline Distraction Period (Days) & 45 & 54 & 53 & 44 & 69 & 54 & 66 & 52 & 58 & 65 \\
\hline External Fixator Removal Time (Days) & 106 & 124 & 122 & 104 & 154 & 124 & 148 & 120 & 132 & 146 \\
\hline Healing Index & 2.40 & 2.29 & 2.17 & 2.53 & 2.44 & 2.38 & 2.27 & 2.50 & 2.40 & 2.39 \\
\hline Distraction Index & 0.97 & 1.00 & 1.05 & 0.93 & 0.91 & 0.96 & 0.98 & 0.92 & 0.94 & 0.94 \\
\hline Maturation Index & 2.40 & 2.3 & 2.2 & 2.5 & 2.4 & 2.4 & 2.3 & 2.5 & 2.4 & 2.4 \\
\hline Consolidation Index & 3.6 & 3.4 & 3.3 & 3.8 & 3.7 & 3.6 & 3.4 & 3.1 & 3.6 & 3.6 \\
\hline Hospital Stay & 15 & 12 & 13 & 11 & 14 & 18 & 13 & 18 & 16 & 19 \\
\hline
\end{tabular}

\begin{tabular}{|c|c|c|c|c|c|c|c|c|c|c|}
\hline Patient & $\mathbf{1 1}$ & $\mathbf{1 2}$ & $\mathbf{1 3}$ & $\mathbf{1 4}$ & $\mathbf{1 5}$ & $\mathbf{1 6}$ & $\mathbf{1 7}$ & $\mathbf{1 8}$ & $\mathbf{1 9}$ & $\mathbf{2 0}$ \\
\hline Age & 31 & 40 & 32 & 36 & 54 & 28 & 22 & 19 & 45 & 36 \\
\hline Target Length & 47 & 55 & 64 & 42 & 49 & 58 & 51 & 67 & 48 & 53 \\
\hline Length Achieved & 47 & 55 & 61 & 42 & 49 & 54 & 49 & 67 & 18 & 53 \\
\hline Distraction Period (Days) & 47 & 55 & 61 & 44 & 50 & 55 & 53 & 70 & 23 & 55 \\
\hline External Fixator Removal Time (Days) & 110 & 126 & 138 & 104 & 116 & 126 & 122 & 156 & & 126 \\
\hline Healing Index & 2.30 & 2.29 & 2.26 & 2.47 & 2.34 & 2.33 & 2.48 & 2.32 & & 2.37 \\
\hline Distraction Index & 1.0 & 1.0 & 1.0 & 0.98 & 0.98 & 0.98 & 0.92 & 0.95 & - & 0.96 \\
\hline Maturation Index & 2.3 & 2.3 & 2.3 & 2.5 & 2.3 & 2.3 & 2.5 & 2.3 & & 2.4 \\
\hline Consolidation Index & 3.5 & 3.4 & 3.4 & 3.7 & 3.5 & 3.5 & 3.7 & 3.5 & & 3.6 \\
\hline Hospital Stay & 13 & 12 & 15 & 11 & 14 & 17 & 12 & 11 & 17 & 13 \\
\hline
\end{tabular}

*=Case developed re-infection (Osteomyelitis), so implants had to be removed and after thorough debridement and lavage docking was done at fracture site thus resulting in shortening of $3 \mathrm{~cm}$. This case was not included for calculating mean healing index, mean distraction index, mean maturation index and mean consolidation index.

\section{Leg Length}

Mean amount of tibia lengthening was $51.7 \mathrm{~mm}$ range (42-67 $\mathrm{mm})$. Leg length equalisation was achieved in 19 cases

$$
(+/-5) \text {. }
$$

\section{Distraction}

Distraction was started at mean 10 days postoperatively. Mean distraction index was 0.97 (0.91-1.05) and mean hospital stay was 14.2 days.

\section{External Fixator}

Mean duration of external fixator was 126.6 (104-148) days with mean healing index of 2.24 (2.17-2.53). 


\section{Maturation}

The mean maturation index was $2.36(2.2-2.5)$.

Consolidation

The mean consolidation index was 3.53 (3.1-3.8).

\section{Operative Time and Blood Loss}

Mean operative time was 140 minutes with mean amount of blood loss of $170 \mathrm{~mL}$.

\section{Ankle Motion}

14 patients had excellent, 4 had good and 2 had fair outcome.

\section{Complications}

One case had proximal locking screw failure-screw had to be exchanged. One case developed pre-mature consolidation, as distraction was started at delayed period due to noncompliance-corticotomy had to be reperformed. Two cases required flap surgeries for cover of bone. One case had pin breakage, which had to be exchanged. Two cases developed decreased dorsiflexion of ankle-both cases regained full range after physiotherapy. ${ }^{3}$ One case of infection occurred in our study, so implants had to be removed and after thorough debridement and lavage docking was done at fracture site thus resulting in shortening of $3 \mathrm{~cm}$.

According to modified scoring by Paley et al, 12 patients had excellent results, 3 patients had good, 4 patients had fair and 1 patient had poor outcome.

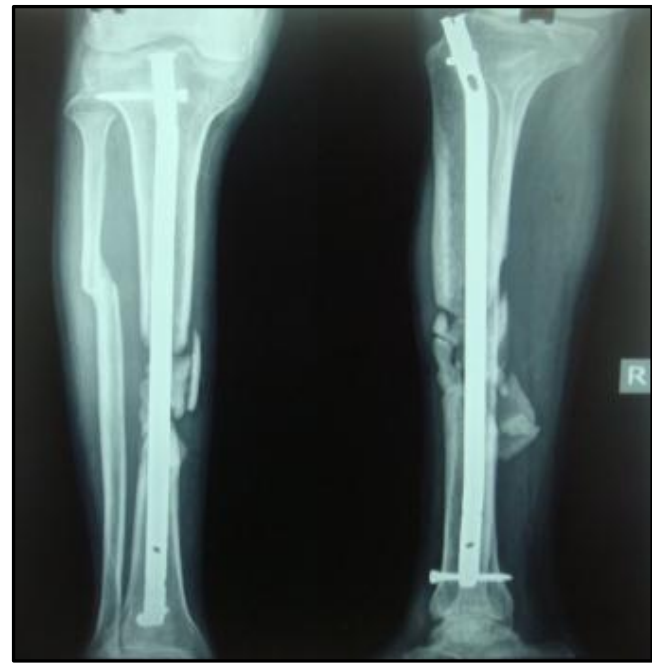

Fig. 1: Preoperative X-Ray: Implant In Situ

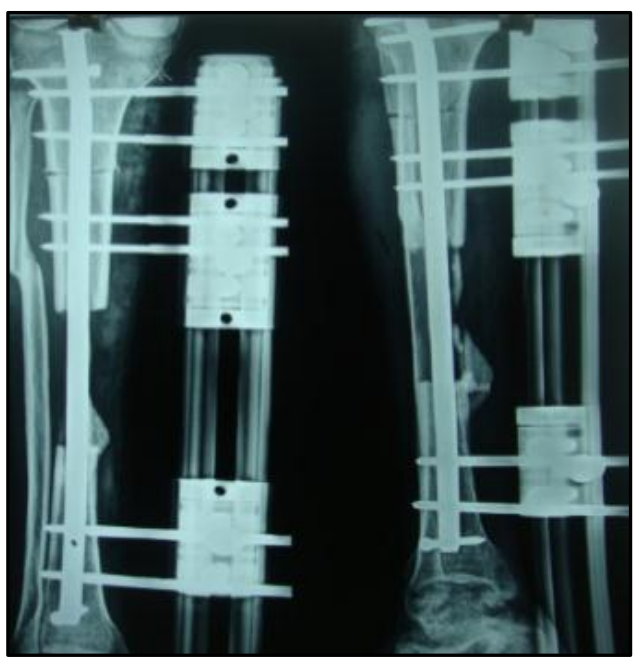

Fig. 2: LRS with IMIL and Corticotomy

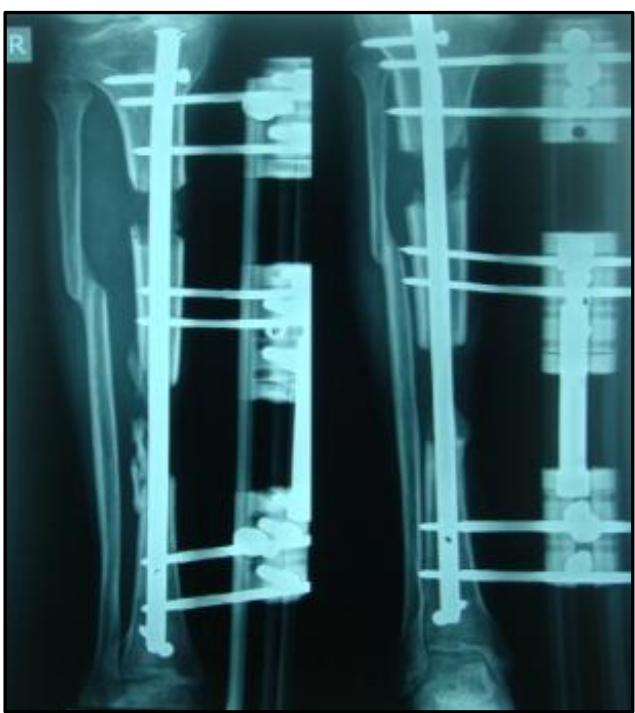

Fig. 3: During Distraction Phase

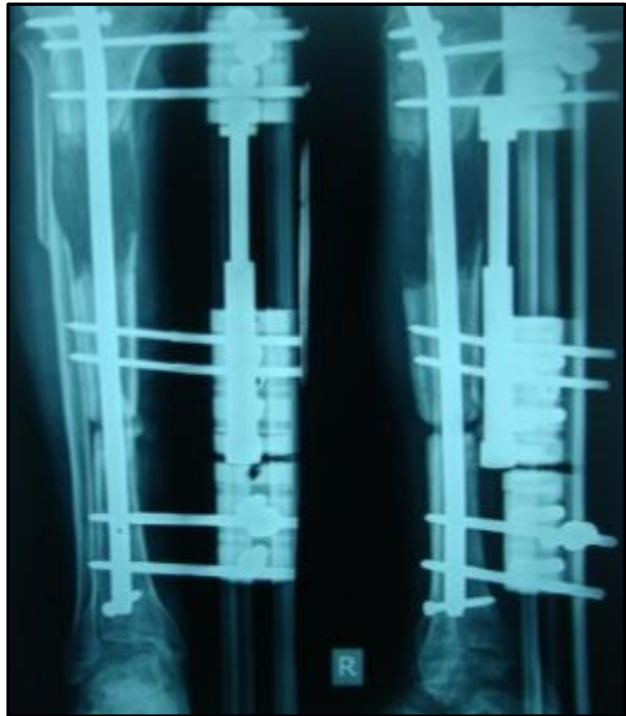

Fig. 4: End of Distraction

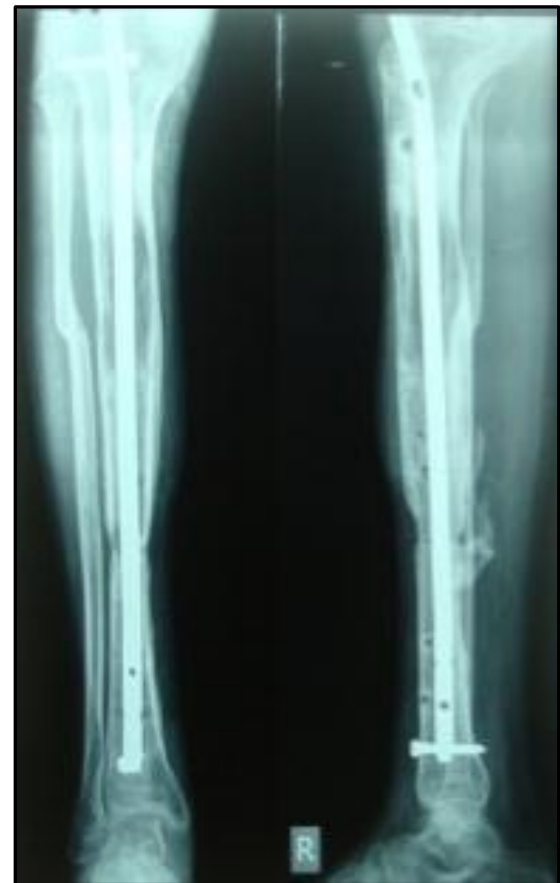

Fig. 5: After LRS Removal once Maturation Phase was Equal to Distraction Phase 


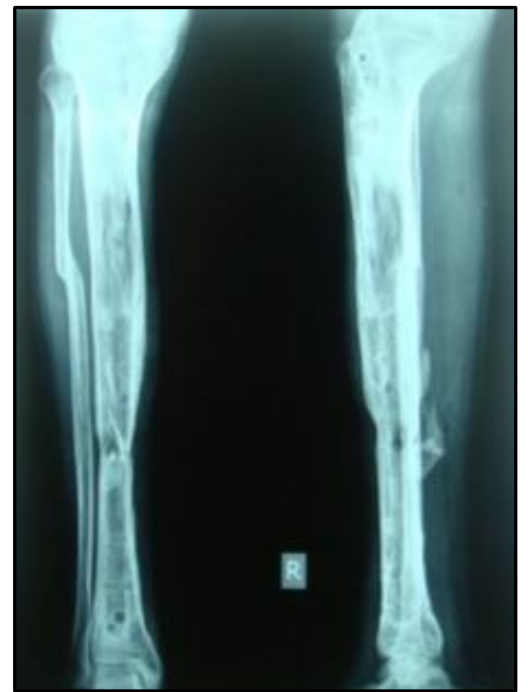

Fig. 6: Follow-Up at One Year

\section{DISCUSSION}

The studies on combined use of Ilizarov external fixator and Intramedullary Interlocking Nail have been published by Paley et $\mathrm{al}^{1}$ in cases of femur and Linh et $\mathrm{al}^{4}$ in tibia. But they were used in cases of shortening with different aetiologies which included congenital ${ }^{2}$ tumours, post-traumatic, bone loss or infective cause. The individuals treated with lengthening over a nail coped better with outdoor activities during the treatment period than the individuals treated with the conventional Ilizarov method. 5 The advantages of lengthening over an intramedullary nail include a decrease in the duration of external fixation, protection against refracture and earlier rehabilitation. ${ }^{6}$ This is an original study done in cases of infected non-union tibia where combined use of Limb Reconstruction System and Intramedullary Interlocking Nail has been successful.

Limb Reconstruction System was used with Intramedullary Interlocking Nail to manage length and alignment in infective non-union tibia. It also helps in diminishing fracture of regenerate by neutralising forces on tibia. It also decreases the mal-alignment, which is encountered with use of Limb Reconstruction System alone.

Although most cases had no major complaints in their last follow-up, 3 cases had mild limp with slight pain resulting in good outcome, 4 patients had decreased range of ankle motion upto neutral with slight pain, mild limp and reduced activity resulting in a fair outcome; 1 case had developed reinfection thus resulting in implant removal and had to undergo shortening of $3 \mathrm{~cm}$. Overall 15 patients had excellent-to-good outcome signifying the efficacy of use of limb reconstruction system along with intramedullary interlocking nail in cases of infected non-union tibia.

Pin prick infection intramedullary infection during lengthening, a concern that is due to the trauma of nailing after external fixation. Although, we did encounter one re infection despite of adhering to strict asepsis followed in operation theatre; twice daily care of pins and also intraoperative care was taken so as to avoid contact between pins and nail.

There are few weaknesses in this study. Our study was limited by the lack of match controlled group, treated with LRS alone. The number of patients is small.
Although the combination of intramedullary nailing and external fixation is technically more demanding than the LRS alone, it has the advantages of a reduction in the duration of external fixation, protection against refracture and earlier rehabilitation. We believe that these advantages offset the disadvantages of increased cost, increased operative time and increased blood loss. In conclusion, we believe that our findings demonstrate that tibial lengthening over an intramedullary nail is safe and reliable and offers advantages compared with the standardmethod of Ilizarov lengthening/limb reconstruction system alone. ${ }^{2,7,8,9,10}$

\section{CONCLUSION}

The advantages of this technique include complete eradication of infective foci, reduced risk of deformity during lengthening, decreased risk of fractures post external fixator removal and reduction of time required for external fixator use thus decreasing healing index: number of days of external fixation required per centimetre of lengthening.

\section{REFERENCES}

1. Vijay C, Kumar M, Manjappa CN. Management of open type III a and III b fractures with LRS external fixator. Internet Journal of Forensic Sciences 2009:22.

2. Paley D. Problems, obstacles and complications of limb lengthening by Ilizarov technique. Clin Orthop Relat Res 1990;250:81-104.

3. Krieg AH, Lenze U, Speth BM, et al. Intramedullary leg lengthening with a motorised nail: indications, challenges and outcome in 32 patients. Acta Orthopaedica 2011;82(3):344-50.

4. Huy'nh BL, Robert FJ. Tibial lengthening over an intramedullary nail. Techniques in Orthopaedics 2009;24(4):279-88.

5. Park HW, Yang KH, Lee KS, et al. Tibial lengthening over an intramedullary nail with use of the Ilizarov external fixator for idiopathic short stature. J Bone Joint Surg Am 2008;90(9):1970-8.

6. Paley D, Herzenberg JE, Paremain G, et al. Femoral lengthening over an intramedullary nail. A matched-case comparison with Ilizarov femoral lengthening. JBJS Am 1997;79(10):1464-80.

7. Stanitski DF, Shahcheragi H, Niker DA, et al. Results of tibial lengthening by Ilizarov technique. J Paed Orthop 1996;16(2):168-72.

8. Besset GS, Morris JR. The use of Ilizarov technique in the correction of lower extremity deformities in children. Orthopaedics 1997;20(7):623-7.

9. Magadum MP, Yadav BCM, Phaneesha MS, et al. Acute compression and lengthening by the Ilizarov technique for infected non-union of the tibia with large bone defects. Journal of Orthopaedic Surgery (Hong Kong) 2006;14(3):273-9.

10. Krishnan A, Pamecha C, Patwa JJ. Modified Ilizarov technique for infected non-union of the femur: the principle of distraction-compression osteogenesis. Journal of Orthopaedic Surgery (Hong Kong) 2006;14(3):265-72. 